\title{
INTERNATIONAL FINANCIAL ORGANISATIONS AND GLOBAL CHILD MORTALITY RATES
}

\author{
ELIAS NosRati
}

Economic policy reforms mandated by the International Monetary Fund (IMF) are known to be socially disruptive and associated with declining health, yet their causal effect on children's life chances is understudied. This paper employs two-way fixed effects panel regressions with instrumental variables to examine the impact of IMF programmes on mortality rates amongst children under the age of 5 per 1,000 live births in 176 countries between 1990 and 2017. IMF programmes are shown to cause up to 90 excess under-5 deaths per 1,000 live births (95\% CI: 50-130). This aggregate effect appears to be driven by large-scale privatisation reforms, which cause up to 132 excess child deaths per 1,000 live births (72-191). These parameter estimates are robust to a range of sensitivity checks. IMF-mandated policies, as currently implemented, are harmful to children's health and must be revised in order to prevent avoidable child deaths. The role of international financial organisations in shaping global health outcomes must be taken seriously by researchers and policy-makers alike.

KEY wORDS: Child mortality, institutional determinants of health, International Monetary Fund.

\section{SIGNIFICANCE STATEMENT}

International Monetary Fund (IMF) programmes are associated with worsening health outcomes, but causal estimates of their impacts remain scarce. Rapid large-scale privatisation reforms are known to increase mortality rates at the population level. Whether structural adjustment programmes and IMF-mandated privatisation reforms impact child mortality rates is unknown. This study uses previously unavailable panel data from 176 countries between 1990 and 2017 and an instrumental variable technique to capture causal effects. The paper provides the first systematic investigation of how IMF programmes affect mortality amongst children under the age of 5 and discovers statistically robust and substantively large adverse effects, especially with respect to privatisation reforms, thus identifying key policy levers for future intervention.

\section{INTRODUCTION}

The International Monetary Fund (IMF) is an influential financial organisation that seeks to foster global macroeconomic stability and growth. It influences the institutional determinants of population health through its conditional lending schemes, known as 'structural adjustment programmes'. Countries across the world that are experiencing economic turmoil may turn to the IMF to secure financial support. However, fresh credit is typically issued on the condition that national governments agree to a wide variety of 
domestic policy reforms, known as 'conditionalities'. The goal of these reforms is to ensure macroeconomic stability through reduced public spending, the privatisation of state-owned enterprises, and other related policy interventions. ${ }^{1-3}$

Consequently, the IMF's structural adjustments programmes can exert profound effects on national health systems, state capacities, and attendant health outcomes. ${ }^{4-6}$ In particular, IMF programmes typically precipitate $(a)$ fiscal retrenchment in the health sector, (b) changing costs of medical drugs and equipment wrought by trade liberalisation, and $(c)$ broader structural transformations in the domains of employment or education that affect the social determinants of health. ${ }^{5}$ Although previous research has identified negative associations between IMF programmes and population health, ${ }^{4-6}$ the causal impact of such programmes on child mortality rates has never been systematically assessed.

Moreover, the rapid privatisation of state-owned enterprises has been shown to fuel mortality crises in recent history by increasing unemployment, reducing public provision of welfare services, and deepening social inequalities. ${ }^{7-10}$ However, research on the link between privatisation and mortality through the lens of structural adjustment remains scarce, and virtually nothing is known about how IMF-mandated privatisation reforms affect children's life chances. To fill these gaps in the extant literature, this paper employs previously unavailable data covering 176 countries between 1990 and 2017, coupled with a compound instrumentation technique suited to isolating exogenous variation in IMF interventions across the world.

\section{Methods}

The outcome variable is the mortality rate per 1,000 live births amongst children under the age of 5, measured across 176 countries between 1990 and 2017. These data are drawn from the World Bank World Development Indicators database. ${ }^{11}$ The key treatment variables are $(a)$ a binary indicator of a country's participation in an IMF programme in a given year and $(b)$ a binary indicator of whether a country has received any privatisation conditionalities under an IMF programme. These variables are taken from the IMF Monitor database. ${ }^{3}$ Macroeconomic control variables — which might influence selection into structural adjustment programmes ${ }^{12}$ and simultaneously predict a country's population health status ${ }^{4}$ - are GDP per capita, ${ }^{11}$ a binary financial crisis indicator, ${ }^{13}$ and foreign reserves in months of imports. ${ }^{11}$ To gauge the political condition of (non-)participating countries, we also control for two measures of democracy - the Polity IV democracy index ${ }^{14}$ and a measure of egalitarian democracy. ${ }^{15}$ The reasoning here is that (egalitarian) democratic countries might be reluctant to accept the implementation of policies that are harmful to society's most vulnerable and they are likely to have better population health profiles to begin with. In addition, a country's political (in)stability is measured via an indicator of coup d'état incidence. ${ }^{16}$ Finally, we control for the average number of years of formal education in a country's female population ${ }^{11}$ - an important predictor of child mortality. Descriptive statistics and data sources are provided in TABLE 1.

To assess the impact of IMF programmes on under- 5 mortality rates, the following datagenerating process is posited:

$$
Y_{i t}=T_{i[t-1]} \beta+X_{i t} \theta+\mu_{i}+\varphi_{t}+\varepsilon_{i t} .
$$

$Y_{i t}$ denotes the outcome variable as measured in country $i$ at time $t ; T_{i[t-1]}$ is one of the two 
Table 1: Descriptive statistics

\begin{tabular}{|c|c|c|c|c|c|}
\hline StATISTIC & $\mathrm{N}$ & MEAN & St. DEV. & MIN & MAX \\
\hline Under-5 mortality rate & 5,068 & 50.9 & 54.3 & 2.1 & 327 \\
\hline IMF programme & 4,874 & 0.3 & 0.5 & 0.0 & 1.0 \\
\hline IMF-mandated privatisation reform & 4,827 & 0.04 & 0.2 & 0.0 & 1.0 \\
\hline GDP per capita & 4,610 & 11,589 & 17,245 & 164 & 111,968 \\
\hline Financial crisis & 4,928 & 0.1 & 0.3 & 0.0 & 1.0 \\
\hline Foreign reserves & 3,818 & 4.4 & 4.7 & 0.002 & 79.2 \\
\hline Democracy index & 4,786 & 3.5 & 6.5 & -10 & 10 \\
\hline Egalitarian democracy & 4,053 & 0.4 & 0.2 & 0.03 & 0.9 \\
\hline Coup d'état & 4,286 & 0.02 & 0.1 & 0.0 & 1.0 \\
\hline Mean years of formal female education & 5,068 & 8.8 & 4.0 & 0.5 & 15.5 \\
\hline
\end{tabular}

Notes: The under-5 mortality rate is per 1,000 live births. The second column lists the number of observed country-years. The two IMF variables are binary variables indicated the presence or absence of IMF programmes or of IMF-mandated privatisation reforms. The democracy index ranges from -10 to 10. The egalitarian democracy index ranges from 0 to 1. Sources: World Bank World Development Indicators, IMF Monitor, Systemic Banking Crises database, The Polity Project, Quality of Government database, and Coups in The World database. 
dichotomous treatment indicators, lagged by one year to allow for effects to manifest; $X_{i t}$ is a vector of control variables; $\mu_{i}$ captures time-invariant country-specific effects; $\varphi_{t}$ measures time-fixed effects; and $\varepsilon_{i t}$ is a stochastic error term. The principal quantity of interest is $\beta$, which is a causal effect parameter to be estimated. To distinguish causal from merely correlational relationships, the paper follows recent advances in the methodological literature on IMF programmes ${ }^{17,18}$ by adopting a compound instrument, $Z$, derived from the interaction between the country-specific average exposure to structural adjustment over the sample period and the number of countries with an IMF programme in a given year, which approximates the Fund's annual budget constraint. ${ }^{12}$ This instrument is relevant insofar as the IMF is likely to impose more stringent loan conditions when facing liquidity concerns. It is also excludable insofar as the Fund's aggregate annual budget constraint is independent of any given client country, such that unit-specific shocks that deviate from a country's long-run average exposure to structural adjustment result from a treatment assignment mechanism that is random with respect to any given country's counterfactual outcomes. Put differently, child mortality rates in countries with varying propensities to participate in IMF programmes will not be affected by changes in the Fund's budgetary constraint other than through the impact of structural adjustment.

In short, the adopted instrumental variable approach hinges on the idea that liquidity concerns lead the IMF to impose harsher loan conditions but are unrelated to any individual country's child mortality profile, thus providing a source of exogenous variation. Any timeinvariant confounders are accounted for by isolating changes in child mortality rates within countries over the sample time period via country-fixed effects, whilst aggregate time trends, such as secular improvements in survival probabilities, that affect all countries simultaneously are controlled for through the use of time-fixed effects. We thus obtain a two-stage regression model with the following linearised selection equation:

$$
T_{i t}=Z_{i t} \tau+X_{i t} \eta+\alpha_{i}+\kappa_{t}+v_{i t}
$$

where $Z_{i t}$ is the value of the compound instrument in country $i$ at time $t$. I then re-specify the model in equation (1) as follows, with $\widehat{T}$ being a vector of fitted values from equation (2):

$$
Y_{i t}=\widehat{T}_{i[t-1]} \beta+X_{i t} \theta+\mu_{i}+\varphi_{t}+\varepsilon_{i t} .
$$

To empirically assess the strength of the chosen instrument, we compare the model in equation (2) to a restricted first-stage regression in which the effect $\tau$ of $Z$ on $T$ is set to be null, obtaining a $\chi^{2}$ test statistic of 50 on 1 degree of freedom $(p<0.001)$. The alternative instrument targeting privatisation reforms also passes the required significance threshold, with a $\chi^{2}$ test statistic of 63 on 1 degree of freedom $(p<0.001)$. Hence, in both cases, $Z$ comfortably satisfies the benchmark for identifying strong instruments. All variance estimators are consistent with serial autocorrelation, heteroskedasticity, and country-level clustering effects. All analyses are conducted in $\mathrm{R}$, version 4.0.2. ${ }^{19}$

Given that the strict exogeneity of the instrument cannot be empirically verified, the persistence of residual unmeasured confounding is conceivable. To address this concern, we perform a simple non-parametric sensitivity analysis that quantifies $(a)$ the change in the parameter estimate $\hat{\beta}$ that would result from adjusting for some hypothesised amount of bias, and $(b)$ the amount of unmeasured confounding that would in theory be required to eliminate the estimated causal effect $\hat{\beta}$ (i.e., reduce it to zero). For these two purposes, let $C$ denote 
an unmeasured confounder. Then the bias factor is defined as the difference between $\hat{\beta}$ and what $\hat{\beta}$ would have been had $C$ been controlled for as well. ${ }^{20}$ The E-value, on the other hand, is defined as the minimum strength of net association that an unmeasured confounder would need to have with both the exposure and the outcome to fully explain away a specific exposureoutcome association. ${ }^{21}$ Though ordinarily defined on the risk ratio scale, the E-value can be adjusted to obtain an approximate (conservative) value on the continuous scale.

\section{RESUlts}

FIGURE 1 visualises the output of a baseline two-way fixed effects instrumental variable regression model. The model tracks within-country changes in child mortality rates across units with and without IMF programmes. Estimation uncertainty is accounted for by simulating from the model sampling distribution. First differences in the outcome variable between the treatment and control groups are then visualised. ${ }^{22}$ Figure 1 shows that, on average, IMF programmes cause 90 excess under-5 deaths per 1,000 live births (95\% CI: 50-130). In percentage terms, this amounts to a $51 \%$ increase in such deaths. FIGURE 2 visualises a similar model, except that the instrumented treatment variable is now centred on IMF-mandated privatisation reforms. The model suggests that the aggregate effect of IMF programmes identified above is most likely driven by the Fund's privatisation policies, which lead to 132 excess child deaths per 1,000 live births (72-191). This is equivalent to a $77 \%$ increase in under-5 mortality rates.

We now assess the robustness of these baseline findings to confounding bias. To avoid multicollinearity issues and losing too many observations at once due to missing data, I insert and remove each control variable one by one and observe the effect this has on $\hat{\beta}$. TABLES 2 AND 3 show that the substantive findings presented in FiguRES 1 AND 2 are fully robust to each of these control variables. The only non-trivial modification of $\hat{\beta}$ is caused by controlling for foreign reserves, which are theoretically a central predictor of IMF programme participation $^{12}$ and could plausibly be linked to child mortality rates insofar as greater reserve holdings would help national governments to bypass at least some of the deleterious effects of exchange rate volatility for the purchase of medicines, medical equipment, or other public health infrastructure. However, the variable is not significantly predictive of the outcome, nor is it significantly associated with structural adjustment in either of the selection equations (not displayed). Interpreting this observed effect attenuation therefore warrants some caution. Either way, the key results from the baseline model remain unaltered from a substantive point of view. As for the remaining covariates, we see (as expected) that egalitarian democracy is a powerful predictor of children's chances of survival, above and beyond the detrimental effects of structural adjustment programmes.

To further assess the sensitivity of $\hat{\beta}$ to unmeasured confounding, we calculate the (approximate) E-value corresponding to the baseline model estimates presented in FIGURES 1 AND 2. In the case of the overall programme model, the unmeasured confounder $C$ would have to increase child mortality rates by around 5 standard deviations - equivalent to 385 excess deaths per 1,000 live births - in order to nullify the estimated treatment effect. In the case of the privatisation model, the corresponding number would be 9 standard deviations, or nearly 700 excess deaths per 1,000 live births. These are exceptionally large net effects that seem implausible. However, for the sake of argument, consider that $\hat{\beta}$ is biased by as much as $50 \%$ in both model specifications. The bias-adjusted parameter 


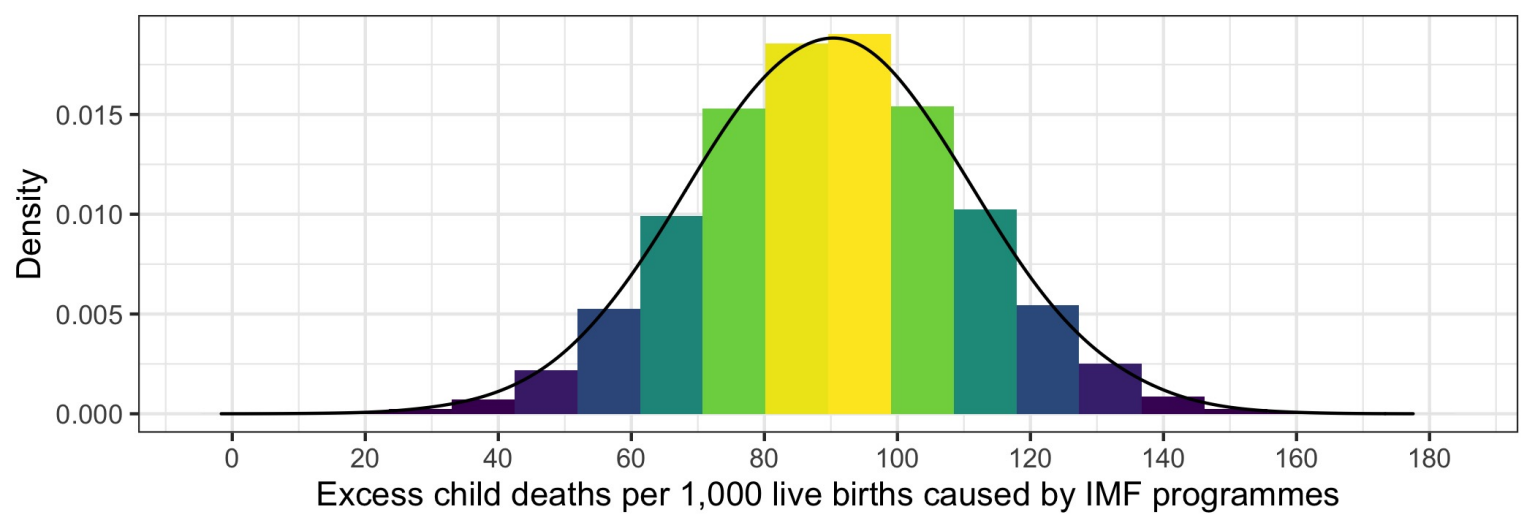

Figure 1: The figure visualises the estimated excess under-5 mortality burden per 1,000 live births caused by IMF programmes. The estimates are derived from two-way fixed effects instrumental variable regression models in which within-country changes in child mortality rates across units with and without IMF programmes are calculated. First differences in the outcome variable are then used to estimate excess death rates. 


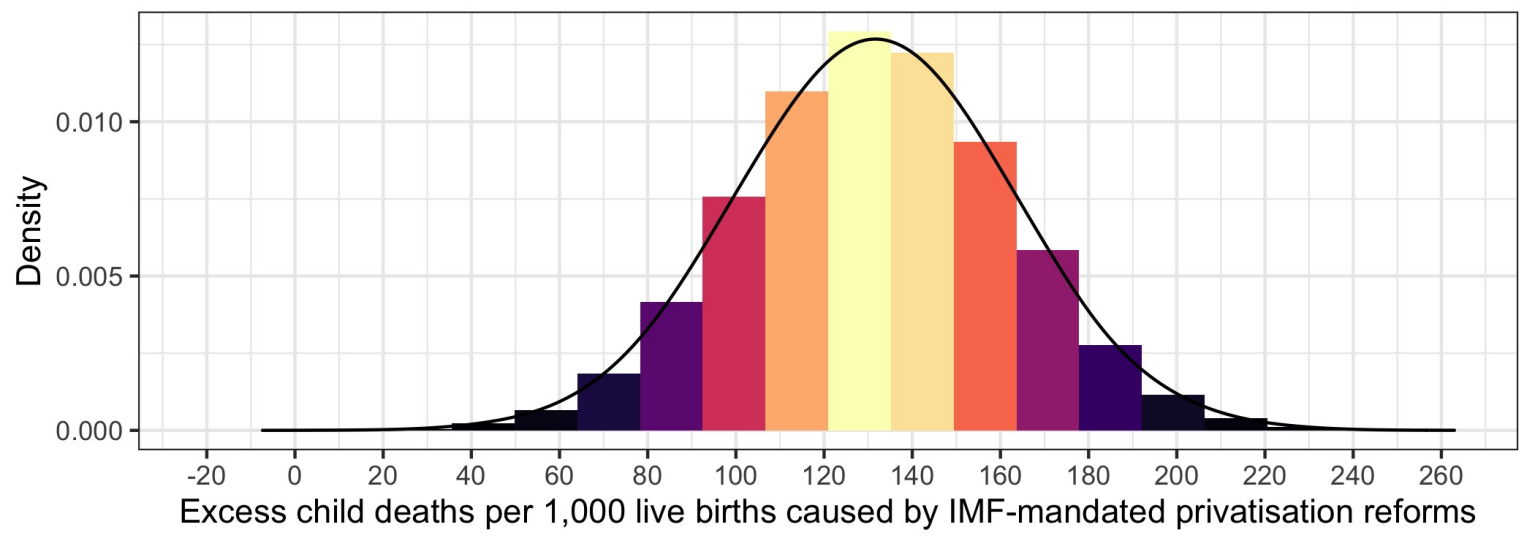

Figure 2: The figure visualises the estimated excess under- 5 mortality burden per 1,000 live births caused by IMF-mandated privatisation reforms. The estimates are derived from two-way fixed effects instrumental variable regression models in which within-country changes in child mortality rates across units with and without privatisation reforms are calculated. First differences in the outcome variable are then used to estimate excess death rates. 
TABle 2: IMF PROGRAMMES AND CHILD MORTALITY RATES

\begin{tabular}{lcc}
\hline \hline Control VARIABle & COntrol COEFFiCIENT & IMF $_{t-1}$ COEFFICIENT \\
\hline Log of GDP per capita & 17 & 97 \\
& $(11)$ & $(23)$ \\
Financial crisis & -5 & 91 \\
& $(5)$ & $(21)$ \\
Foreign reserves & -0.05 & 65 \\
& $(0.3)$ & $(18)$ \\
Democracy & -2 & 87 \\
& $(0.6)$ & $(19)$ \\
Egalitarian democracy & -127 & 87 \\
& $(39)$ & $(22)$ \\
Coup d'état & 5 & 92 \\
& $(5)$ & $(25)$ \\
Female education & -0.8 & 91 \\
& $(3)$ & $(20)$ \\
\hline \hline
\end{tabular}

Notes: The outcome variable is the annual under-5 mortality rate per 1,000 live births between 1990 and 2017. Each row is a separate two-way fixed-effects regression wherein the effect of IMF programmes on all-cause mortality is adjusted for the control variable listed in the first column. All models are also adjusted for country- and time-fixed effects. The IMF variable, lagged by one year, is instrumented as described in the DATA AND METHODs section. The corresponding parameter estimate is interpreted as the excess number of child deaths per 1,000 live births caused by structural adjustment. Standard errors consistent with serial autocorrelation, heteroskedasticity, and unit clustering are shown in parentheses below each parameter estimate. 
TABle 3: IMF-MANDATED PRIVATISATION REFORMS AND CHILD MORTALITY RATES

\begin{tabular}{lcc}
\hline \hline Control variable & Control COEFFicient & PRIVATISATION $_{t-1}$ COEFFICIENT $^{2}$ \\
\hline Log of GDP per capita & -9 & 134 \\
& $(5)$ & $(32)$ \\
Financial crisis & 5 & 130 \\
& $(3)$ & $(30)$ \\
Foreign reserves & -0.01 & 104 \\
& $(0.2)$ & $(35)$ \\
Democracy & -1 & 127 \\
& $(0.3)$ & $(32)$ \\
Egalitarian democracy & -71 & 120 \\
& $(21)$ & $(36)$ \\
Coup d'état & 5 & 123 \\
Female education & $(5)$ & $(40)$ \\
& 0.3 & 131 \\
\hline \hline
\end{tabular}

Notes: The outcome variable is the annual under-5 mortality rate per 1,000 live births between 1990 and 2017. Each row is a separate two-way fixed-effects regression wherein the effect of IMFmandated privatisation reforms on all-cause mortality is adjusted for the control variable listed in the first column. All models are also adjusted for country- and time-fixed effects. The privatisation variable, lagged by one year, is instrumented as described in the DATA AND METHODs section. The corresponding parameter estimate is interpreted as the excess number of child deaths per 1,000 live births caused by privatisation conditionalities. Standard errors consistent with serial autocorrelation, heteroskedasticity, and unit clustering are shown in parentheses below each parameter estimate. 
estimates would then be 45 (5-85) and 66 excess child deaths per 1,000 live births (6-125), respectively. These are still substantively important effect sizes, even after adjusting for a very large bias factor.

\section{Discussion}

This paper's empirical focus on child mortality fills an important gap in the extant literature. Although a handful of studies have investigated the impact of IMF programmes on children's health, ${ }^{4,23,24}$ the present paper advances the state of the art by using previously unavailable data and follows recent methodological advances to identify causal effects, documenting remarkably robust empirical evidence of a substantively large deleterious impact of structural adjustment programmes on under-5 mortality rates. In particular, privatisation reforms mandated by the IMF seem to be particularly harmful to children's life chances. The sensitivity analysis suggests that the principal findings are robust even to inordinate amounts of unmeasured confounding.

For lack of richer multilevel data, the paper cannot detail the precise causal mechanisms at work. However, previous scholarship has provided insights into a series of potential pathways. In particular, the key mechanisms linking structural adjustment to population health have been described as falling into three major categories. ${ }^{5}$ The first pertains directly to the functioning of health systems across four principal dimensions, namely $(a)$ the financing of healthcare, which the IMF shapes by mandating cuts in public health spending; ${ }^{25,26}(b)$ the quality of care provision, which is impacted by the migration of key workers away from hiring freezes, wage cuts, and increased redundancies wrought by IMF-sponsored fiscal retrenchment in the health sector; ${ }^{25,27}(c)$ healthcare coverage, which is reduced by the Fund's promotion of user fees or co-payments coupled with changing eligibility criteria; ${ }^{28,29}$ and $(d)$ the organisational capacities of health systems in the wake of decentralisation, outsourcing, and privatisation reforms. ${ }^{26,30}$ Children's survival chances are sensitive to the functional capacities of health systems, especially in the perinatal and infant stages, and are thus directly affected through these four dimensions.

The second category encompasses a range of mechanisms indirectly pertaining to the functioning of health systems. These involve the potential spillover effects of currency devaluation and trade liberalisation on the cost of (imported) medicines and equipment or the value of tax revenues that fund the health sector. ${ }^{31,32}$ In addition, since state-owned enterprises often provide health coverage and other welfare benefits to their employees, privatisation reforms can reduce access to healthcare and related social services. ${ }^{7-9}$ Also here, these indirect effects are likely to impact child mortality rates by influencing maternal stress and (in)security levels or the quality of care received during critical aetiological windows in early life.

The third category pertains to the broader social determinants of health, including (un)employment, poverty, education, and social cohesion. Economic dislocations wrought by mass redundancies, wage declines, exchange rate volatility, or reduced social expenditure are likely to induce widespread psychosocial stress. ${ }^{12,33-35}$ By acting upon and sometimes amplifying these social forces, IMF programmes shape the circumstances in which local populations are born, grow, live, work, and age, thereby influencing the central parameters of human life chances. ${ }^{36}$ For instance, children can experience malnourishment as a result of hikes in food prices in the wake of current and capital account liberalisation or as a result of 
parental unemployment, which has profound effects on their early health and development. ${ }^{37}$

The paper's emphasis on privatisation reforms is motivated by previous research having shown that the rapid privatisation of state-owned enterprises is associated with rising unemployment and labour market precariousness, reduced public provision of welfare services, including housing and healthcare, as well as weaker social cohesion and state capacities. ${ }^{10}$ These factors, in turn, have driven large upticks in working-age mortality rates, resulting in one of the most salient declines in population health in recent history, namely the post-Communist mortality crisis. ${ }^{9-7}$ However, until now, the link between privatisation and mortality has not been probed through the lens of structural adjustment, especially with respect to children's survival.

Future research should seek to explicitly connect the findings of this paper to these hypothesised pathways. Nevertheless, the implications of the present work for future policy-making are substantial. IMF-mandated privatisation reforms are especially harmful and must be revised in order to prevent avoidable child deaths. The role of international financial organisations in shaping children's health must be taken seriously by researchers, policy-makers, and clinicians alike.

\section{REFERENCES}

1. Babb S, Carruthers BG. Conditionality: forms, function, and history. Ann Rev Law Soc Sci 2008; 4:13-29.

2. Babb S. The social consequences of structural adjustment: recent evidence and current debates. Ann Rev Sociol 2005; 31:199-222.

3. Kentikelenis AE, Stubbs TH, King LP. IMF conditionality and development policy space, 1985-2014. Rev Int Polit Econ 23(4):543-582.

4. Forster T, Kentikelenis AE, Stubbs TH, King LP. Globalization and health equity: The impact of structural adjustment programs on developing countries. Soc Sci Med 2020; 267:112496.

5. Kentikelenis AE. Structural adjustment and health: a conceptual framework and evidence on pathways. Soc Sci Med 2017; 187:296-305.

6. Stuckler D, Basu S. The International Monetary Fund's effects on global health: before and after the 2008 financial crisis. Int J Health Services 2009; 39(4):771-781.

7. Azarova A et al. The effect of rapid privatisation on mortality in mono-industrial towns in post-Soviet Russia: a retrospective cohort study. Lancet Public Health 2017; 2(5):e231-e238.

8. Scheiring $G$ et al. The gendered effects of foreign investment and prolonged state ownership on mortality in Hungary: an indirect demographic, retrospective cohort study. The Lancet Global Health 2018; 6(1):e95-e102.

9. Stuckler D, King LP, McKee M. Mass privatisation and the post-communist mortality crisis: a cross-national analysis. Lancet 2009; 373(9661):399-407. 
10. Stuckler D, Basu S. The Body Economic: Why Austerity Kills. Penguin, 2013.

11. WDI, n.d. World Bank World Development Indicators. https://datacatalog.worldbank.org/dataset/world-development-indicators. Accessed 1 April 2021.

12. Vreeland JR. The IMF and Economic Development. Cambridge University Press, 2003.

13. Laeven L, Valencia F. Systemic banking crises database. IMF Econ Review 2013; $61(2): 225-270$.

14. Center for Systemic Peace, n.d. The Polity Project. https://www.systemicpeace.org/ polityproject.html. Accessed 1 April 2021.

15. Quality of Government Database, n.d. https://www.gu.se/en/quality-government/ qog-data. Accessed 1 April 2021.

16. Powell J, Thyne C. Global Instances of Coups from 1950-Present. J Peace Research 2011; 48(2):249-259.

17. Lang V. The Democratic Deficit and Its Consequences: The Causal Effect of IMF Programs on Income Inequality. Rev Int Organ 2020; https://doi.org/10.1007/s11558-020-09405-x.

18. Stubbs TH, Reinsberg B, Kentikelenis AE, King LP. How to Evaluate the Effects of IMF Conditionality. Rev Int Organ 2018; 15:29-73.

19. R Core Team. 2020. R: A language and environment for statistical computing. Vienna, Austria: R Foundation for Statistical Computing.

20. Vanderweele TJ, Arah OA. Bias formulas for sensitivity analysis of unmeasured confounding for general outcomes, treatments, and confounders. Epidemiol 2011; $22(1): 42-52$.

21. Vanderweele TJ, Ding P. Sensitivity Analysis in Observational Research: Introducing the E-Value. Ann Intern Med 2017; 167(4):268-274.

22. King G, Tomz M, Wittenberg J. Making the Most of Statistical Analyses: Improving Interpretation and Presentation. Am J Pol Sci 44:341-355.

23. Daoud A, Nosrati E, Reinsberg B, Kentikelenis AE, Stubbs TH, King LP. Impact of International Monetary Fund programs on child health. Proc Natl Acad Sci USA 114(25): 6492-6497.

24. Daoud A, Reinsberg B. Structural adjustment, state capacity and child health: evidence from IMF programmes. Int J Epidemiol 2019; 48(2):445-454.

25. Kentikelenis AE, Stubbs TH, King LP. Structural adjustment and public spending on health: Evidence from IMF programs in low-income countries. Soc Sci Med 2017; 126:169-76. 
26. Stubbs TH, Kentikelenis AE, Stuckler D, McKee M, King LP. The impact of IMF conditionality on government health expenditure: A cross-national analysis of 16 West African nations. Soc Sci Med 2015; 174:220-227.

27. Marphatia AA. The adverse effects of International Monetary Fund programs on the health and education workforce. Int J Health Services 2009; 40:165-178.

28. Maresso A et al., eds. Economic Crisis, Health Systems and Health in Europe: Country Experience. Open University Press, 2015.

29. Thomson S et al., eds. Economic Crisis, Health Systems and Health in Europe: Impact and Implications for Policy. Open University Press, 2015.

30. Kentikelenis AE et al. Greece's health crisis: from austerity to denialism. Lancet 2014; 383(9918):748-753.

31. Breman A, Shelton C. Structural adjustment programs and health. Pp. 219-233 in Globalization and Health. Kawachi I, Wamala S. Oxford University Press, 2006.

32. Baunsgaard T, Keen M. Tax revenue and (or?) trade liberalization. J Public Econ. 2010; 94:563-577.

33. Dreher A. IMF and economic growth: the effects of programs, loans, and compliance with conditionality. World Dev 2006; 34:769-788.

34. Forster T, Kentikelenis AE, Reinsberg B, Stubbs TH, King LP. How Structural Adjustment Programs Affect Inequality: A Disaggregated Analysis of IMF Conditionality, 1980-2014. Soc Sci Res 2019; 80:83-113.

35. Vreeland JR. The effect of IMF programs on labor. World Dev 2002; 30:121-139.

36. Marmot Review. 2010. Fair Society, Healthy Lives. Institute of Health Equity.

37. Handa S, King D. Adjustment with a human face? Evidence from Jamaica. World Dev 2003; 31(7):1125-1145. 